\title{
Management of Crown-root Fractures: A Report of Two Cases
}

\author{
Arun Sarath Baabu ${ }^{1}$, Mathan Rajan Rajendran ${ }^{2}$, Manigandan Kuzhanchinathan ${ }^{3}$, Ganesh Arathi ${ }^{4}$
}

\begin{abstract}
Maxillary anteriors are the most commonly affected teeth in dental traumatic injuries. Crown-root fracture is one type of traumatic injury with several treatment modalities existing for management. One of them is the reattachment of the fractured fragment in a suitable condition. Fragment reattachment provides immediate esthetics and function and is also less time-consuming procedure. If the fragment is lost, other alternatives such as direct and indirect restorations may be considered. The purpose of this report is to present two cases describing the management of complicated crown-root fractures of maxillary anterior teeth treated with a multidisciplinary approach.

Keywords: Crown-root fracture, Dental trauma, Fragment reattachment, Indirect restoration.

Journal of Operative Dentistry and Endodontics (2020): 10.5005/jp-journals-10047-0088
\end{abstract}

\section{INTRODUCTION}

Dental injuries are most common among all the facial injuries of which crown fractures occur most frequently. ${ }^{1}$ The largest proportion of injuries affecting the permanent dentition are seen in anterior teeth, the majority of which are the maxillary central incisors, followed by maxillary lateral incisors, mandibular incisors, and maxillary canines being less frequent. ${ }^{2}$ This is due to their position in the arch, where malocclusions with increased overjet, protruded anteriors, and incompetent lips are the key predisposing factors. Traumatic dental injuries involve varying degrees of damage to the tooth with or without its impact over the supporting soft tissues as well. Factors that influence the management of these fractures include the extent of the fracture, pattern of fracture, restorability of the fractured segment, secondary injuries, presence/absence of fractured tooth fragment, and its accountability, occlusion, and esthetics, apart from patient factors. ${ }^{3,4}$ Therefore, the treatment modalities for individual cases differ from one another, as they demand both esthetic and functional components to be met at the earliest, especially for the anterior teeth. Unlike other coronal fractures, crown-root fracture (also known as oblique fracture) requires special attention, as it necessitates interdisciplinary interventions. The fractured fragments were often minimally displaced and being kept in their position by fibers of the periodontal ligament. When the fractured fragment remains intact with adequately preserved margins, adhesive reattachment of the fragment is a viable treatment option. ${ }^{5}$ Fragment reattachment offers substantial benefits for both the clinician and the patient, as it requires less chairside time, providing immediate esthetics that maintains the tooth's original anatomic form, color, and surface texture. Being a relatively simple and inexpensive procedure, it also restores function, provides desirable wear rate, and a positive psychological response. ${ }^{6}$ Direct or indirect restorations can be used when the fractured fragment is not available or not suitable for the reattachment procedure. ${ }^{7}$ The following case reports describe the management of crownroot fractures of maxillary central and lateral incisors treated in a multidisciplinary approach.
${ }^{1-4}$ Department of Conservative Dentistry and Endodontics, Faculty of Dental Sciences, Sri Ramachandra Institute of Higher Education and Research, Chennai, Tamil Nadu, India

Corresponding Author: Arun Sarath Baabu, Department of Conservative Dentistry and Endodontics, Faculty of Dental Sciences, Sri Ramachandra Institute of Higher Education and Research, Chennai, Tamil Nadu, India, Phone: +91 9789086304, e-mail: arunsarath92@ gmail.com

How to cite this article: Baabu AS, Rajendran MR, Kuzhanchinathan M, et al. Management of Crown-root Fractures: A Report of Two Cases. J Oper Dent Endod 2020;5(1):45-50.

Source of support: Nil

Conflict of interest: None

\section{Case Descriptions}

\section{Case 1}

A 19-year-old male patient reported to the Department of Conservative Dentistry and Endodontics, Faculty of Dental Sciences, Sri Ramachandra Institute of Higher Education and Research, with the chief complaint of pain in his mobile upper front teeth for the past 2 days. He had a history of sports injury, where the cricket cork ball blew over the chin region 2 days before. Extraoral examination revealed contusions in the upper and lower lips. Intraoral examination showed complicated crown-root fracture in relation to 21,22 with tenderness on vertical percussion. A mobile coronal fragment was present in relation to 22 , supported by periodontal ligament fibers palatally, as the supra-gingival margin of this oblique fracture was present on the labial aspect. The fractured coronal fragment of 21 was not available, as it was lost in the injury site. The probing depth was $2 \mathrm{~mm}$ in labial and proximal aspects and $3 \mathrm{~mm}$ lingually in relation to 22 , while there was no clinically evident loss of attachment in 21. In addition to it, a complicated crown fracture was evident in relation to 32 associated with tender on percussion and a healthy pocket depth (Figs $1 \mathrm{~A}$ and B). Radiographic interpretation revealed coronal fracture line involving the pulpal

() The Author(s). 2020 Open Access This article is distributed under the terms of the Creative Commons Attribution 4.0 International License (https://creativecommons. org/licenses/by-nc/4.0/), which permits unrestricted use, distribution, and non-commercial reproduction in any medium, provided you give appropriate credit to the original author(s) and the source, provide a link to the Creative Commons license, and indicate if changes were made. The Creative Commons Public Domain Dedication waiver (http://creativecommons.org/publicdomain/zero/1.0/) applies to the data made available in this article, unless otherwise stated. 
space with closed apex in relation to 22 (Fig. 1C) with no evidence of crestal bone loss and root or bone fracture. To exclude the presence of fractured fragments of 21 and 32, a radiograph of upper and lower lip was taken with one-fourth of the hard tissue radiation dose. After the complete clinical and radiographic examination, the patient was given treatment option of endodontic therapy for 21,22 , and 32 , followed by fragment reattachment of 22 along with fiber reinforced composite (FRC) postendodontic restoration for 21 and 32. After the deliberation of detailed treatment plan with advantages, disadvantages, prognosis, and the treatment cost, the patient was willing to proceed for reattachment option of 22, as the fragment was in good and suitable condition for the procedure.

Administration of local anesthesia (2\% Lignocaine) by labial infiltration was done following the mouth rinse with $0.2 \%$ chlorhexidine. Cotton roll isolation with cheek retractor in position was done, since the rubber dam clamps might severe the fragment and the remaining tooth structure, which is essential for the adhesive procedure. Fractured fragment in relation to 22 was removed and stored in saline solution to eliminate the possible dehydration of fragment. The gingival aspect of the fractured site lingual to 22 revealed a knife-edge fracture margin extending subgingivally (Fig. 1D). On probing the fractured margin, biologic width was adequate, and thus bone recontouring was not done.

Single-visit nonsurgical endodontic treatment was performed in relation to 22 with obturation using cold lateral compaction technique. Post-space preparation was done in relation to 22 for glass FRC post, leaving $5 \mathrm{~mm}$ of apical gutta-percha plug for adequate seal, and verification radiograph was taken to confirm the length (Fig. 1E). The coronal end of the FRC post was cut with slowspeed diamond disks such that $4 \mathrm{~mm}$ of the post is available above the coronal surface of the remaining tooth structure to enhance the retention of the fragment. Gingivoplasty was performed with laser on the palatal aspect of 22 in order to keep the fracture margin supragingivally to prevent soft-tissue impingement and to enhance the bonding of fragments (Fig. 1F). Then, the pulp chamber space in the detached fragment was cleansed with 3\% sodium hypochlorite to remove the pulpal remnants in order to avoid possible discoloration of the fragment after reattachment. The chamber space was then prepared with high speed round bur such that it approximates to the coronal portion of FRC post, meeting the fractured margins without any gap. The knife-edge margins of the fragment were finished using diamond burs and Sof-Lex disks to achieve a passive seating and approximation of the fragments. Using $37 \%$ orthophosphoric acid, both the tooth structure and the fragment were etched for 30 seconds, rinsed, and blot-dried; then, FRC post was luted to the canal using self-adhesive resin luting cement, following which cementation of the prepared fragment after accurate approximation was done along with light curing. Initially, 5 seconds of tack-curing was done in order to remove the excess cement and then complete photo-polymerization done for 40 seconds in accordance with the manufacturer's instructions (Fig. 1G). Occlusal evaluation was done and relieved from the contact with the antagonist tooth. All these procedures pertaining to the 22 were done in single visit (Fig. $1 \mathrm{H}$ ), along with the initiation of root canal therapy in 21 and 32 was done.

In the following appointments, nonsurgical endodontic treatment was performed in 21 and 32 under rubber dam isolation. Since both the fractured fragments of 21 and 32 were lost at the time of injury, postendodontic management of 21 was carried out with custom-made cast post and full coverage crown, and in relation to 32 full coverage crown was given. A sequential follow-up was carried out up to 3 years for all the treated teeth which remained normal with both function and esthetics till date (Fig. 11).

\section{Case 2}

A 23-year-old male patient reported to the department complaining of fracture in his upper front teeth along with intermittent, localized pain in his fractured teeth for the past 1 week. The patient had a history of road traffic accident a week before, in which he underwent a blow injury over his upper lips. Extraoral examination revealed healing contusions in the upper lips and right malar region of his face. Intraoral examination revealed a complicated crown-root fracture in relation to 11 which was tender on palpation and percussion. The oblique fracture line was found supragingivally in the labial aspect and subgingivally toward the mesiolingual aspect of 11 along with uncomplicated crown fracture evident in relation to 21 and 12 with no tenderness on palpation and percussion (Fig. 2A). The fractured coronal fragments of 11, 21, and 12 were lost at the site of injury. Radiographic interpretation in relation to 21 revealed coronal fracture line involving the pulpal space with the mature apex and no evidence of root and bone fracture (Fig. 2A). Nonsurgical root canal treatment followed by postendodontic management with FRC post, and full coverage crown in relation to 11 was planned. On pulp sensibility testing both 21 and 12 responded within normal limits; thus, restorative management and sequential follow-ups for review were planned. After the deliberation of detailed treatment plan, the patient agreed to undergo the treatment.

After achieving a profound anesthesia ( $2 \%$ Lignocaine) under rubber dam isolation, single-visit endodontic treatment was done in relation to 11 with obturation using lateral compaction technique (Fig. 2B), followed by immediate post-space preparation and gingivoplasty on the mesiolingual aspect without bone recontouring using diode laser (Bio-lase) in order to achieve a supragingival fracture margin (Fig. 2C).Then, the FRC post was cemented using self-adhesive resin cement, and composite core buildup was done (Brilliant NG-Coltene) (Fig. 2D). Inadvertent extrusion of sealer that occurred during obturation of 11 was kept under observation throughout the recall period, which did not cause any signs and symptoms and did not interfere with the periapical healing. All ceramic crown preparation was done and cemented with self-adhesive resin cement in relation to 11 in the subsequent visit (Fig. 2E). Restorative management of 12 and 21 carried out with composite restoration. The patient was followed up sequentially for 1 year in which the endodontically treated 11 remained asymptomatic clinically and showed adequate healing radiographically with normal function and esthetics (Fig. 2F). With regard to 21 and 12, pulp sensibility tests were carried out at the follow-up intervals and both the teeth responded within normal limits throughout the 1 year follow-up.

\section{Discussion}

Epidemiological studies have presented that approximately onesixth of the adolescents and one-fourth of the adults suffer a traumatic dental injury in their lifetime and most of the traumatic dental injuries involve just one tooth. ${ }^{8,9}$ Crown fractures account for up to $92 \%$ of all types of traumatic injuries to the permanent dentition. ${ }^{10}$ However, the frequency of crown-root fractures has shown to be $5 \%$ in permanent dentition, while it is $2 \%$ in primary dentition, and maxillary anteriors are the most commonly affected teeth. ${ }^{11}$ Chisel type of fracture in these anteriors obliquely splits the 

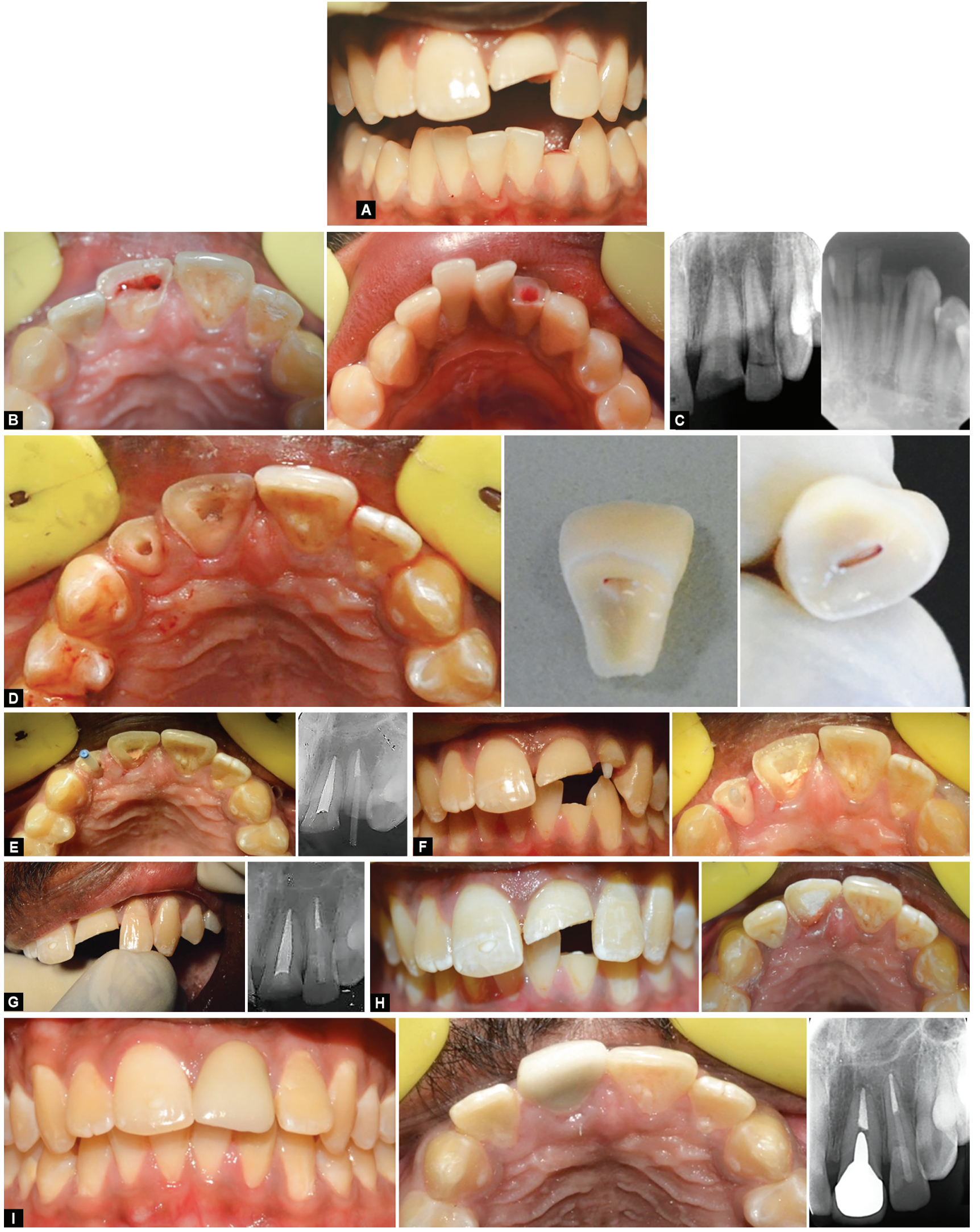

Figs 1A to I: (A) Preoperative intraoral photograph-labial view; (B) Preoperative intraoral photograph-occlusal views of maxillary and mandibular anteriors; (C) Preoperative intraoral periapical radiograph; (D) Fragment removed irt 22 and the fragment; (E) FRC post Tryln; (F) FRC post preparation and laser gingivectomy irt 22; (G) Fragment approximation and reattachment and postoperative radiograph; $(\mathrm{H})$ Immediate postoperative photograph of 22; (I) Three-year follow-up 

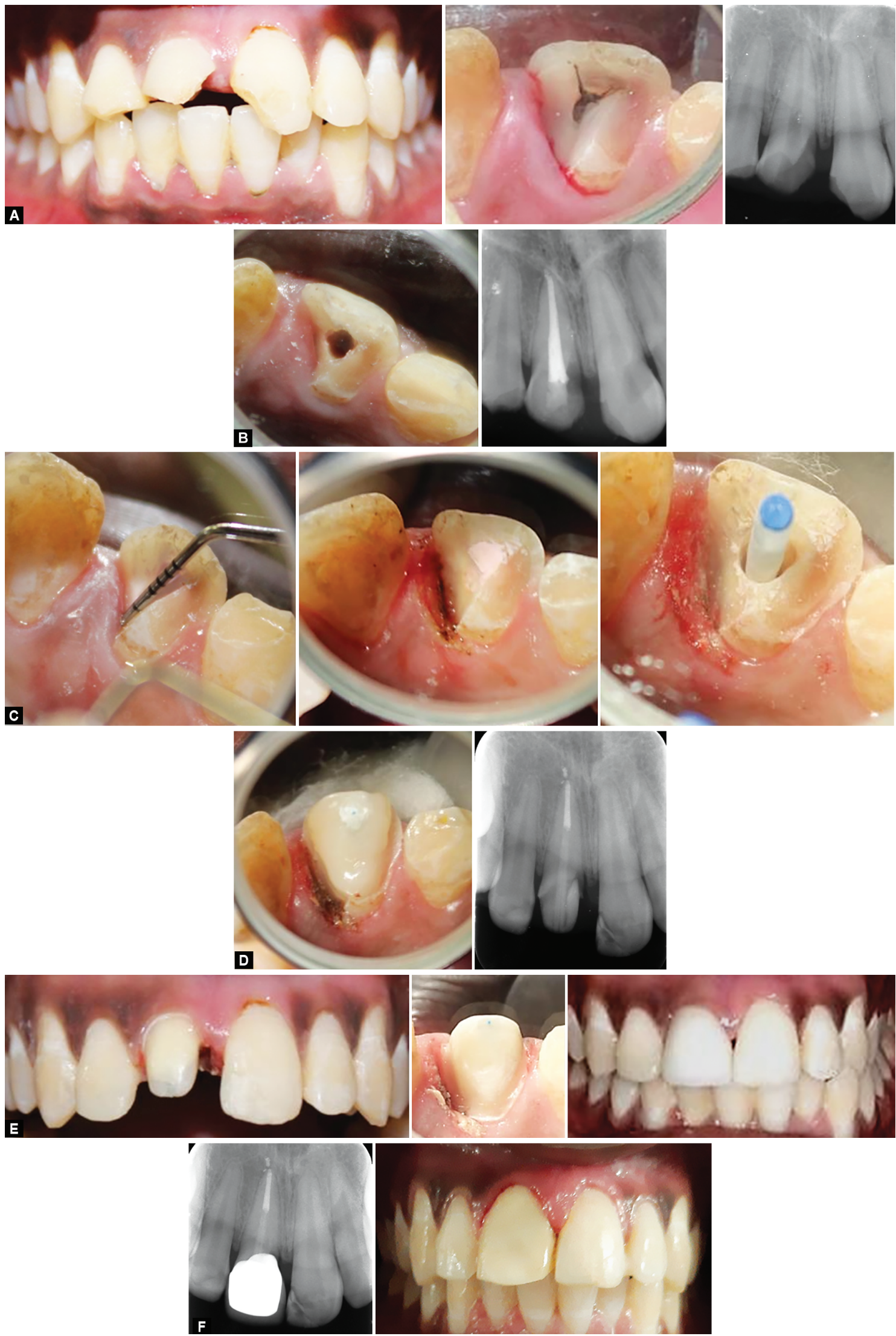

Figs $2 \mathrm{~A}$ to F: (A) Preoperative photographs and radiograph; (B) Endodontic treatment irt 11; (C) Laser gingivectomy and FRC post Tryln; (D) FRC post cementation and composite core buildup; (E) Tooth preparation and all ceramic crown cementation; (F) Postoperative radiograph and 1 year follow-up 
portion of both crown and root. Biological consequences depend on the periodontal complications in addition to pulpal involvement, as encroachment of the attachment apparatus exists in the crownroot fractures. These types of fractures necessitate a wide range of treatment modalities that might require endodontic-periodonticorthodontic-surgical continuum or their combinations. ${ }^{11,12}$ Therefore in restoring these fractures, an interdisciplinary approach should be considered. Advancement in adhesive systems and resin composites has made the reattachment of tooth fragments, a procedure that is no longer considered as provisional management, instead a definitive treatment with a favorable prognosis.

Sjogren et al. stated that following a crown-root fracture, endodontic therapy is a viable treatment option with a higher success rate in mature tooth. ${ }^{13}$ In our first case, fractured 22 was managed with endodontic therapy followed by post-placement and fractured fragment attachment. To enhance the long-term retention of the coronal fragment, post placement was done before the fragment attachment. ${ }^{14}$

Dental practitioners have used an assortment of bevel designs, chamfers, dentinal, and enamel grooves and use of different types of adhesive systems and, different intermediate materials in addition to various techniques for the reattachment of tooth fragments. A systematic review on different tooth fragment reattachment techniques stated that simple reattachment with no preparation is considered to be the currently preferred technique when there is complete fragment adaptation, compared to other reattachment techniques using overcontouring and dentinal groove preparation. ${ }^{15}$ Increase in the bond strength between tooth fragment and dentin is observed when an intermediate material was used. These results are in par with another systematic review on tooth reattachment techniques by de Sousa et al. ${ }^{16}$ Since the fractured fragment was well adapted, simple reattachment without any preparation was carried out in our first case along with the use of self-adhesive resin cement as intermediate material. A study by Hedge proves that saline as storage medium has the highest fracture resistance when compared to other media such as milk, and the best storage period is 24 hours. ${ }^{17}$ Our case did not necessitate for storage, as the fragment was within the oral cavity, held by the periodontal attachment apparatus. During the period of the treatment procedure, the fragment was stored in saline until it is reattached back to its original position. The FRC post is luted to the root canal, followed by the fragment with the use of self-adhesive resin cement, rather composite resins, considering that the viscosity and dual-cure mechanism of these adhesive resin cements which facilitate the chemical polymerization, as the deeper portions of the luting interfaces may not be light polymerized.

In the second case, since the patient lost the tooth fragment at the site of trauma, reattachment was not possible. Hence, endodontic management followed by FRC post along with full coverage crown was done. If the fracture margins are supragingival, the reattachment procedure would be simple. However, if it is subgingival or intraosseous with violation of biological width, orthodontic or surgical extrusion may be necessary. Alternatively, surgical techniques such as electrosurgery, elevation of tissue flap, clinical crown lengthening by laser, or surgery along with or without osseous reduction enable access to the fractured site. However, the biologic width can restore by itself in cases with minimal biologic width invasion, provided adequate plaque control is achieved. ${ }^{6}$ Therefore, the prognosis of the crownroot fracture would also depend on the contour and surface finishing of the subgingival restoration along with postoperative maintenance. Laser gingivectomy was performed in both the cases pertaining to the lingual aspect of the fractured teeth to make the fracture margins supragingival, thus achieving adequate isolation for predictable bonding of the FRC post and the fragment or core material.

To retain the core and to reinforce the cervical portion of the tooth, an intracanal FRC post was used. It has been studied that long, thin fiber post is effective for reducing tensile stresses that can lead to fracture of endodontically treated anterior tooth. ${ }^{18}$ The success rates of reattached fragments have shown to be up to $90 \%$ based on 2 year follow-up period studied by Yilmaz et al..$^{19}$ In our case report, the first patient was followed up periodically for the past 3 years, the second patient was followed up for the past 1 year, and the teeth were asymptomatic clinically and radiographically along with the normal form, function, and esthetics. Both the patients were motivated and advised for periodic follow-ups to perform clinical and radiographical examinations to ensure the esthetics, integrity, and functional health of the managed teeth.

\section{Conclusion}

This case report emphasizes the importance of appropriate treatment plan and clinical management of crown-root fractures. With the remarkable advents of materials available today, in conjunction with appropriate techniques, crown-root fractures can be managed with predictable outcomes offering favorable prognosis. Whenever the fragment is available, its reattachment to its original position is a viable treatment option. However, based on the individual clinical scenarios, direct or indirect restorations can also be considered.

\section{References}

1. Andreasen JO, Andreasen F, Andersson L. Textbook and Color Atlas of Traumatic Injuries to the Teeth. 4th ed., Oxford: Blackwell Munksgaard; 2007.

2. Hedge MN, Sajnani AR. Prevalence of permanent anterior tooth fracture due to trauma in south Indian population. Eur J Gen Dent 2015;4:87-91. DOI: 10.4103/2278-9626.154183.

3. Olsburgh S, Jacoby T, Krejci I. Crown fractures in the permanent dentition: pulpal and restorative considerations. Dent Traumatol 2002;18(3):103-115. DOI: 10.1034/j.1600-9657.2002.00004.x.

4. Andreasen FM, Noren JG, Andreasen JO, et al. Long term survival of fragment bonding in the treatment of fractured crowns. Quintessence Int 1995;26(10):669-681.

5. Baratieri LN, Ritter AV, Junior SM, et al. Tooth fragment reattachment: an alternative for restoration of fractured anterior teeth. Pract Periodont Aesthet Dent 1998;10(1):115-127.

6. Thapak G, Arya A, Arora A. Fractured tooth reattachment: a series of two case reports. Endodontology 2019;31:117-120. DOI: 10.4103/ endo.endo_140_18.

7. Eden E, Yanar SC, Sönmez Ş. Reattachment of subgingivally fractured central incisor with an open apex. Dent Traumatol 2007;23(4):184-189. DOI: 10.1111/j.1600-9657.2005.00408.x.

8. Shulman JD, Peterson J. The association between incisor trauma and occlusal characteristics in individuals 8-50 years of age. Dent Traumatol 2004;20(2):67-74. DOI: 10.1111/j.1600-4469.2004.00234.x.

9. Shayegan A, De Maertelaer V, Abbeele AV. The prevalence of traumatic dental injuries: a 24 month survey. J Dent Child 2007;74(3):194-199.

10. Divakar HD, Nayak M, Shetty R. Changing concepts in fracture reattachment of teeth-a case series. Endodontology 2007;2: 27-35. 
11. Abbott PV. Endodontics and dental traumatology-an overview of modern endodontics. In: Endodontist 1999.

12. Flores MT, Andersson L, Andreasen JO, et al. Guidelines for the management of traumatic dental injuries. I. Fractures and luxations of permanent teeth. Endod Topics 2006;14(1):102-118. DOI: 10.1111/j.1601-1546.2008.00234.x.

13. Sjogren $U$, Hagglund $B$, Sundqvist $G$, et al. Factors affecting the longterm results of endodontic treatment. J Endod 1990;16(10):498-504. DOI: 10.1016/S0099-2399(07)80180-4.

14. Maitin N, Maitin SN, Rastogi K, et al. Fracture tooth fragment reattachment: case report. BMJ Case Rep 2013;2013:bcr2013009183.

15. Garcia FCP, Poubel DLN, Almeida JCF, et al. Tooth fragment reattachment techniques-A systematic review. Dent Traumatol 2018;34(3):135-143. DOI: 10.1111/edt.12392.
16. de Sousa APBR, Franca K, de Lucas Rezende LVM, et al. In vitro tooth reattachment techniques: a systematic review. Dent Traumatol 2018;34(5):297-310. DOI: 10.1111/ edt.12414.

17. Hedge RJ, Kale SJ. Comparison of the effect of various storage media on the fracture resistance of the reattached incisor tooth fragments: an in vitro study. Indian. J Dent Sci 2017;9:233-236.

18. Nakamura T, Ohyama T, Waki T, et al. Stress analysis of endodontically treated anterior teeth restored with different types of post material. Dent Mater J 2006;25(1):145-150. DOI: 10.4012/dmj. 25.145.

19. Yilmaz Y, Zehir C, Eyuboglu O, et al. Evaluation of success in the reattachment of coronal fractures. Dent Traumatol 2008;24(2): 151-158. DOI: 10.1111/j.1600-9657.2007.00532.x. 